\title{
TRAUMATIC PARAPLEGIA PRE-GUTTMANN
}

\author{
T. B. S. DICK, M.D., F.R.C.P.
}

THE first recorded reference to spinal injuries is to be found in the Edwin Smith Surgical Papyrus written some 4000 years ago. The unknown author comments briefly on a cervical spine injury with cord involvement: 'one having a crushed vertebra of his neck. He is unconscious of his two arms and two legs and is speechless. An ailment not to be treated' (Breasted, 1930; Elsberg, I93I). One is bound to record that even in modern times the sentiments thus expressed by the ancient surgeon cannot be regarded as completely outmoded.

Hippocrates, about 400 B.C., makes mention of the spinal cord while Celsus and Aretaeus of Cappodocia in the first and second centuries A.D. respectively both refer to the functions of the spinal cord (Dinken, 1943). Paralysis of the extremities, urinary incontinence, priapism and involuntary ejaculation of semen had by then been observed as occurring in association with injury to the spine. It is interesting to note that Galen in the first century A.D. carried out certain experiments on the effects of trauma on the spinal cord. He observed that a longitudinal slit in the cord had no demonstrable effect on function, whereas a transverse incision produced paralysis of the body below that level. The significance of these findings appears to have passed unnoticed for many centuries though in the seventh century A.D. Paulus Aegineta advised operation for fracture of the spine. His advice was apparently ignored, and perhaps in the light of modern knowledge with reason, but one may at least marvel at his temerity (Courville, I937).

In I 545 Fabricius Hildanus once again referred to the possibility of surgery in such cases but it was left to Louis in $\mathbf{7 7 7 4}$ to perform the first operation for the cure of spinal injury (Kuhn, 1947).

Position of Rehabilitation of Paraplegics up to and immediately after World War I. Until World War I, and possibly even later, little hope could be held out to the sufferer with traumatic paraplegia. The attitude to such a one is well expressed by the writer who said: 'It is a matter of preserving life by constant and meticulous care when life is of little value to the patient and costly to his relatives ... and not infrequently some surgeons have been persuaded by the importunate family to explore. In such a case the Physician is relieved of his distressing duty' (Courville, 1937).

Haynes (1946) mentions that Cushing in his report as Senior Consultant in Neurological Surgery to the American Army during World War I discussed spinal cord injuries only to lament their almost invariably pitiable fate and early death.

In the Balkan wars the mortality was over 95 per cent. for this type of injury (Poer, 1946), and in World War I it was very little less. Kuhn (1947), giving the American figures for that war, states that only 20 per cent. of cases survived long enough to be evacuated to America and only Io per cent. of the latter survived for a further year. It is estimated that only I per cent. survived for more than 20 years. The British figures are very similar.

Thomson-Walker (1937) believed that the overall mortality was not less than 80 per cent. after three years and that it was probably higher. The Medical Re- 
search Council report on spinal cord injuries published in 1924 does not give any survival figures but does indicate that the survival period depends on the severity of the injury, i.e. whether it was a complete or partial lesion, the prognosis of course being much better in the latter. In the former it was considered very bad. It is not altogether surprising that in this otherwise excellent report there is a paucity of information concerning treatment and a complete absence of a section dealing with the late management or rehabilitation of the paraplegic.

The British literature of this period contains many excellent papers on spinal cord injuries, notably those by Riddoch (I9I7), Riddoch and Head (I9I 7), Holmes (I9I 5), Frazier and Allan (I9I8) but they deal with the problems of neurophysiology and pathology, neurosurgery and the like, and are little or not at all concerned with therapy. Gordon Holmes (I915) in his Goulstonian Lectures on spinal cord injuries devotes one short section only to treatment. Thomson-Walker (I9I7), Vellacott and Webb-Johnson (I9I9), Besley (I9I7), Kidd (1919), Young (I926) and others did write on the early management of the bladder, but later papers on this aspect serve mainly to stress the enormous mortality from urinary sepsis. The inference is, therefore, that the outlook in these cases-at all events in the ones with complete lesions-was too hopeless and the question of rehabilitation did not arise. There is no doubt, however, that some men did survive for many years (Gowland, I934).

Martin (1947) succinctly puts the situation thus: 'The record attained in World War I is not a very enviable one and it is quite apparent that the methods of treatment of traumatic paraplegia were not improved by the rich experience of that War'.

The Position between the Wars. Denny-Brown and Robertson (I933) Learmonth (1930), Holmes (1933) and Watkins (1936) published important papers, on the neurophysiology of the normal and the cord bladder, and in the later 'thirties Munro (1935) in America was beginning to publish the earliest of his many articles on tidal drainage. There is, however, little literature directly bearing on paraplegic management in this period, but a paper read by Gowland to the Harveian Society in London in 1934 is particularly pertinent as it gives a very informative picture of the stage rehabilitation of these cases had reached at this time. Gowland was Medical Superintendent of the Star and Garter Home where there were a number of patients with chronic traumatic paraplegia, survivors from World War I. He writes: 'Perhaps somewhere about I I.30 a.m. the patient is dressed and placed in a wheelchair. ... T Two to three times a week the patient is bathed. This means he must be lifted from his bed to his ward chair and wheeled into the bathroom where his pyjamas and night clothes are removed and he is placed in a very warm bath and washed by an orderly.' These men were neither expected nor allowed to do anything for themselves. He continued: 'These painful contractures (spasms) are a very serious problem ... the pain is often terrible. I suppose there is more morphia, atropine and hyoscine used in this home which I look after than in any other place of the same size in the country, but when you consider that these patients cannot be cured. ...' With regard to the bladder and bowels he writes: 'Orderlies have instructions to go round between one and two a.m. to remove, empty and replace urine bottles. Not infrequently the patient's bowels have moved and he is lying in his excrement.' '. . . Patients spend one or two days a week entirely in bed. These are called enema days.' Again with regard to bed 
sores: 'In all these cases the circulation of the skin below the injured area is deficient ... the skin will break down under quite minor irritations'.

These brief quotations serve to bring out several points, namely that these men were in no way able to look after themselves, nor were they encouraged to do so. It would appear probable that owing to the prevailing attitude of hopelessness many had been allowed to become drug addicts. Nothing could be clearer than that these survivors were but shadows of their former selves, pathetic wrecks, dependent and helpless and the recipients of much devoted but misguided care. Nor is there any reason to doubt that these conditions were materially different anywhere else in this or in any other country in the world. Indeed, to show the attitude of despondency it is only necessary to quote verbatim the Medical Research Council (I924) report previously mentioned: 'The paraplegic patient may live for a few years in a state of more or less ill-health'.

Manifestly when these patients did survive for long periods survival was unexpected and little appears to have been done in an attempt to enable them to achieve any sort of independence of mind or body. Penicillin and the sulphonamides, to say nothing of the more modern antibiotics, were not available to this generation at war. Had they been, without doubt there would have been many more survivors to swell the numbers in these chronic homes. It seems probable that owing to the lack of such drugs, which help so much in tiding the patient over the early hazards of bedsores and urinary sepsis, a state of mind was engendered in which the future of these cases was regarded as hopeless. The fact that a few survivors were left as pathetic wrecks, dependent and helpless, to be cared for in homes and hospitals for the chronic sick probably largely escaped notice.

The Position during the Early Years of World War II. In the early days of this war the authorities in Britain made two decisions of some moment with regard to the care and treatment of spinal cord injuries. The first was that these cases should, as soon as was practicable, be sent to hospitals designated as spinal injury centres where a neurosurgical team was working. The second decision was that where it was evident that retention of urine associated with traumatic paraplegia was likely to be of prolonged duration, i.e. had not passed off in 48 hours, a suprapubic cystotomy was to be the method of choice for bladder drainage (Jefferson, 1948).

Thomson-Walker in 1937 had reviewed the methods of bladder drainage in the spinal injuries of World War I. Most of the cases he saw were dealt with by intermittent catheterisation and he was impressed by 'the lamentable tale of surgical failure'. The total death rate from urinary sepsis he estimated at 80 per cent. He, therefore, advocated suprapubic cystotomy. Barrington, Everidge and Morson (1942), Riches (1942) and others similarly advocated high suprapubic cystotomy. Knight (I940) recommended suprapubic cystotomy placed just above the symphysis pubis.

The importance of a high suprapubic incision was not sufficiently appreciated in the early years of the war. While the vast majority of cases admitted to spinal injury centres had suprapubic cystotomies, many were situated very low on the abdominal wall, a method which became almost universally condemned. As to other aspects of therapy little was said or written. Knight in 1942 advocated the use of plaster beds. MacAlpine (1940) considered that when bedsores appeared in the form of black blisters the contents should be aspirated and the black skin left 
intact-advice which all subsequent experience proved to be unacceptable. Nissen in 1940 and I94I, in the light of his recent experiences, also advocated plaster beds, but be it noted that in the same paper he was quoting 'Thou shalt not kill; but needst not strive officiously to keep alive'. This quotation is in no way invoked to indicate that his results were bad, but it does show an attitude of mind fatal in dealing with these cases, and in the writer's experience it was prevalent even as late as the end of 1944. Everts and Woodhall were able to write in I944: 'It certainly cannot be said that any striking advance has been made in the late care of spinal cord injuries'.

A Spinal Injury Unit in the North of England 1940-1944 (Winwick). This special centre at Winwick was a mental hospital in peace-time and was partially taken over by the Ministry of Health. Special centres in neurosurgery, orthopaedic surgery, medical neurology, peripheral nerve and spinal injuries were set up. General medical and surgical cases were to a limited extent also admitted. A neurosurgical team was in charge of this spinal injury unit, but no one member of the team devoted more than a part of his time to the care of spinal injury cases. In theory, paraplegics were to be transferred to a specialised spinal unit as rapidly as possible after injury. In practice, it was not uncommon for them to be received several months after injury and rare for them to be received in the first two or three weeks. They came from general hospitals, military and civilian, and occasionally from spinal centres to be nearer their homes. In general, the cases were in poor condition on arrival at the centre. The great majority of severe cord or cauda equina lesions of whatever level, had bedsores often large and multiple. Virtually all had suprapubic cystotomies variously placed, and all had gross urinary infection.

To facilitate the nursing problems, well-fitting anterior and posterior plaster beds were largely used, and while in no way advocating this method (the disadvantages of which had been stressed by Guttmann (1945) and Munro (1940) and others), undoubtedly healing of sores did take place in some cases though in others new sores formed and old ones were aggravated. This method, in view of the extreme shortage of nurses, did enable frequent turning to be easily and rapidly carried out and had some advantages. A wide variety of antiseptics were used in dressing the sores but sloughs were not excised. Bladder therapy consisted of daily washouts through tube and funnel, using boric or potassium permanganate solutions. Various urinary acidifiers and antiseptics were given by mouth; blood transfusions, penicillin and sulphonamides were given where general systemic disturbance seemed to indicate a necessity for their use. There did not appear to be any definite plan of rehabilitation of even the more fit patients. In 1944 there were 40 paraplegics distributed over six different wards. In each of these wards there were also orthopaedic, neurosurgical and general surgical cases. The nursing staff looking after the spinal injuries did not specialise in that work and were required to nurse cases of other types and were frequently moved to other wards. The number of trained staff was so inadequate that a high proportion of dressings for the chronic and 'hopeless' cases was performed by untrained nurses. A very small proportion of the patients with cord or cauda equina lesions were able to sit out of bed in a chair. At that time the hospital did not possess a single padded wheelchair and the amount of physiotherapist's time available was ridiculously inadequate. The mental attitude of both patients and staff wasone of stoic apathy. Penicillin and sulphonamides were used liberally and may well have enabled many 
cases to survive. Rehabilitation at this time seemed to have progressed no further if as far, as that described by Gowland (1934).

From observation of cases admitted to this centre from other spinal centres in different parts of the country it seemed extremely likely that conditions prevailing there were similar.

The Beginning of the Guttmann Era. In I 944 at Winwick there was a feeling of almost desperation among the medical staff about the paraplegics, not only in relation to the immediate treatment but also about what was to become of them should they survive. I was working on the Medical Neurology and Peripheral Nerve Injury Unit at that time and did not have anything directly to do with the cases of traumatic paraplegia. Sir Geoffrey Jefferson, Adviser in Neurosurgery to the E.M.S. and in particular Consultant Adviser to Winwick, asked me to give up some of my work on the Medical Neurology Unit and take charge of all the cases of traumatic paraplegia in the hospital.

Within a very short time I was voicing my complaints and ideas about concentration of cases into one unit, continuity of treatment, staffing inadequacy, etc. He listened patiently to my tale of woe and then said: 'You must go and see a chap called Ludwig Guttmann at Stoke Mandeville Hospital. He has got ideas about the rehabilitation of the paraplegics'. I must confess that at that time I had never heard of Ludwig Guttmann or Stoke Mandeville. I went to Stoke Mandeville for three days. New ideas and new techniques in paraplegic rehabilitation were beginning to emerge from various places, but it seemed that at Stoke Mandeville these ideas were being put into practice in a well-equipped and well-organised Unit.

I wrote a long report for Sir Geoffrey Jefferson about what I had learned, which was a great deal. What I found extremely difficult to convey to him and to others was Ludwig Guttmann's concept of the paraplegic as a disabled but healthy independent person, with an independent future in society. The enthusiasm for this concept, which emanated from Sir Ludwig and permeated the whole of his staff, was a break-through in new thinking. This was the vital thing, an idea which had never before been seriously entertained.

It was an exhilarating experience, enhanced when later I worked at Stoke Mandeville as Sir Ludwig's first assistant. It seemed to me that this was the beginning of a new era in the rehabilitation of the paraplegic, and so it was. What happened in this new era is for others to describe.

\section{REFERENCES}

Barrington, F. J. F., Everidge, J. \& Morson, A. C. (I942). Proc. R. Soc. Med. 36, 197. Besley, F. A. (I9I7). F. Am. med. Ass. 69, 638.

BREASTED, J. H. (1930). The Edwin Smith Surgical Papyrus, Vol. I, p. 453. University of Chicago Press.

Courville, G. B. (1932). In Practice of Medicine, p. I39, ed. Tice, F. Rogerstown, Md.: Prior.

Denny-Brown, D. \& Robertson, E. G. (1933). Brain, 56, I49.

Dinken, G. (I943). Med. Clins. N. Am. 27, I077.

Elsberg, C. A. (1931). Ann. med. Hist. 3, 27 I.

Everts, W. H. \& Woodhall, B. (1944). F. Am. med. Ass. 126, I 45.

Frazier, C. H. \& Allan, A. R. (I9I8). Surgery of the Spine and Spinal Cord. New York: Appleton.

Gowland, E. L. (1934). Med. Press, I88, 8I.

GuttmanN, L. (1945). Med. Times, N.Y. 73, 318. 
Haynes, W. G. (1946). Am. F. Surg. 72, 424.

Holmes, G. (1915). Br. med. F. 2, 769, 815, 855 .

HOLMES, G. (1933). Brain, 56, 383.

JefFerson, G. (I948). Personal communication.

KIDD, F. (I919). Lancet, I, 397.

KNIGHT, G. (I940). Postgrad. med. F. 16, 249.

KuHN, W. G. (1947). F. Neurosurg. 4, 40.

LEARMONTH, J. R. (I93I). Brain, 54, I 47.

LEARMONTH, J. R. \& BraAsCH, W. F. (I930). Surgery Gynec. Obstet. 5I, 494.

MacAlpine, D. (1940). Practitioner, 144, 337.

MARTIN, J. (I947). Int. Abstr. Surg. 84, 403.

MEDICAL RESEARCH CoUnCIL (I924). Report No. I24.

Munro, D. (1935). New Engl. F. Med. 212, 229.

Munro, D. (1936). New Engl. F. Med. 214, 617.

Munro, D. (1937). Am. F. Surg. 38, I20.

Munro, D. (1940). New Engl. F. Med. 223, 391.

Munro, D. (1943a). F. Am. med. Ass. 122, 1055.

Munro, D. (1943b). New Engl. F. Med. 229, 919.

Nissen, K. I. (I942). Proc. R. Soc. Med. 35, 707.

Poer, D. H. (1946). Ann. Surg. 123, 510.

RIches, E. W. (I942). Proc. R. Soc. Med. 36, 198.

RIDDOCH, G. (I9I7). Brain, 44, 265.

RIDDOCH, G. \& HEAD, H. (I9I7). Brain, 40, I88.

THOMSON-WALKER, Sir J. (I9I7). Lancet, I, I 73 .

Thomson-Walker, Sir J. (I937). Proc. R. Soc. Med. 30, I233.

Vellacott, P. N. \& WeBb Johnson, A. E. (I919). Lancet, I, 733.

Watkins, K. (I936a). Br. F. Surg. 23, 734.

Watkins, K. (1936b). Proc. R. Soc. Med. 30, I240.

Young, H. H. (I926). Practice of Urology, Vol. I. Philadelphia: Saunders. 